\title{
THE EYE HOSPITAL AT SHIKARPUR, INDIA
}

BY

\author{
Robert Buxton, M.B., D.O.M.S.
}

WESTON-SUPER-MARE

SHIKARPUR is a town in the north of Sind, on the Quetta railway, where annually for a few weeks ophthalmic and other diseases are treated. The success of the hospital is largely due to the inspiration and energy of one man-Sir Henry Holland. He went there in 1910 and his own words describe that first year: "it would be well nigh impossible to operate under worse conditions. We had no hospital, no operating theatre, no room where there was sufficient light to do our work, and a large dirty verandah had to serve as operating theatre, out-patient room and dressing-room all thrown into one. When I think of that crowd of 200 to 300 surging around as we operated, constantly raising the dust, which often lay thick over our instruments in the trays, it is a marvel that our success was as great as it was, and at the end of the visit I had clearly made up my mind that under no circumstances would I repeat my visit unless there were facilities where we could operate with greater prospect of success." Conditions nowadays, though far from ideal, are very much better. At the beginning of each year he and his assistants go there and stay for about eight weeks. Operations cease by February 20 owing to the increasing flies, dust and heat. Sir Henry Holland himself is a medical missionary of the Church Missionary Society at Quetta and the hospital is run under the auspices of that society.

I was fortunate enough to be one of the three visiting ophthalmic surgeons this year, and we did 3,400 operations including 1,427 cataract extractions. Sir Henry Holland is also assisted by his son, two English sisters, two expert assistants in the operating rooms, a clerk, some dressers and compounders, and four stretcherbearers acquired locally whose handling of cataract cases filled one with alarm. The eye-hospital, while it lasts, may be claimed to be the largest in the world. During the busiest time there are between 600 and 800 patients accommodated in the wards with a rather larger number of relations and friends. During these few weeks between 6,000 and 8,000 out-patients are dealt with. The hospital itself is a plain building with an out-patient hall, treatment room, dark room and two operating theatres. The latter are used continually throughout the day. Work starts before 9 a.m. and sometimes does not finish until 6.30 p.m. The patients are mainly from Sind and Baluchistan, with a few from further parts such as the Punjab and North-west Frontier Province. There are some six different languages spoken. Sir Henry Holland has been in India 
for most of his life and has an intimate knowledge of the customs and languages of the people. He sees every patient on arrival. Patients sometimes consult the village astrologer as to the best phase of the moon in which to consult the doctor, and this may result in treatment being postponed until too late. Unless the case is hopeless, treatment or operation is advised and the patient waits in the appropriate room. A certain number of general surgical cases are dealt with in a different room from major eye operations, and these include haemorrhoids, hernia, bladder, stone and tumours. Those recommended for operation pass straight into the operating theatre and there patiently wait, so that often a dozen are crouched upon the floor there. If kept outside they often think they are being swindled out of their operation and struggle to get in. Patients present an endless variety of types and temperaments. For instance the apprehensive over-nourished Hindu is in marked contrast to the silent and placid Mohammedan.

The wards are open "serais," the largest accommodating some 300 patients. Outside these are to be found a selection of Indian peasants with their camels, horses, bullock-carts and pie-dogs. Inside, during the busiest part of the season, there is an extraordinary sight. Everywhere are patients, their relatives and their friends. The cataract cases are given "charpoys" or native string beds, and the rest sleep on the floor. Every available square yard of floor is utilized in this way, while any space is filled with cooking utensils, fires, firewood and food. It is not easy to go round the ward without treading on a recumbent human being often hidden beneath a pile of rugs, or bumping one's head on the low ceiling and dislodging a swarm of torpid flies. A marked lack of personal cleanliness and ideas on sanitation, a nearly universal prevalence of trachoma and oral sepsis, and a tendency of the patients to undo their bandages, rub their eyes and test their vision, added to the fact that there are only two trained sisters, do not provide ideal conditions for ophthalmic work.

Ophthalmic cases include cataract of all kinds, glaucoma, leucoma, trichiasis, entropion, trachoma, corneal ulcer, staphyloma, occluded pupil, pterygium, symblepharon, mucocele, and tumours. The latter often being large and fungating. Glaucoma cases amount to about 10 per cent. of all cases. They were mostly of the chronic type and acute congestive glaucoma was a rarity. The number of inoperable glaucomatous eyes was very disappointing and it was sad to have to turn away a patient who had come a many days' journey. Leucomata are very common. These are often due to corneal ulcer and this often is a complication of small-pox. It is considered a sign of good luck to be visited by the goddess of small-pox. On two occasions a youth came in complaining of his eye and in each case there was a corneal ulcer with the rash of active 
small-pox on his face. Unqualified practitioners are wont to treat cases of coma by the application of caustic to the eyes with disastrous results to the corneae.

There are no facilities for bacteriological examination before operation and so great is the amount of work that there would not be time for it. If the case is suitable, operation is done at once unless there is acute trachoma or other infection, or a mucocele. Operative risks are thus taken with many patients. If only selected cases were operated upon, there would be many hundreds of people still blind who at present enjoy useful vision. Most of those turned away would resort to the Indian couchers for relief which is usually only temporary and often results in secondary glaucoma or panophthalmitis. Another difficulty to be faced is the absolute untrustworthiness of the history given by the patient in most cases. Often they wilfully deceive in the hopes of having an operation and will positively affirm that they have perception of light and often guess at counting fingers. Others again who believe that no operation will be done unless the patient is completely blind, will deny that they can see hand movements or the flashing of a light. Among operative risks which have to be taken are the removal of both cataracts from a patient at once, or extracting a cataract from an eye the tension of which is slightly raised.

Some idea of the amount of work may be given by the fact that over 750 out-patients have been seen in a day. On the busiest day this year the total number of operations was over 170, including 96 cataract extractions. In 1923 Dr. Fisher, of Chicago, did 100 cataracts himself on the busiest day, and in 1924 he exceeded this with 114. This amount of work in itself militates against the best results. Before describing the cataract operations mention will be made of the treatment of various diseases. Every operation is recorded and described in a book as well as in a note kept with the patient. Subconjunctival injections of saline are used for a variety of conditions, early pannus, trachoma, early corneal opacities, phlyctenular ulcers. Sir Henry Holland is convinced of their value in many cases and patients have returned as many as ten times for further injections, obviously pleased with results. For severe pannus peritomy is performed round the circumference of the eye about $4 \mathrm{~mm}$. from the limbus with firm pressure from the silver nitrate stick. I saw no untoward results from this treatment and often considerable improvement. For trachoma in severe cases 1:100 hydrarg. perchlor. is applied to the everted lids, after scraping with a sharp spoon. For mild cases zinc lotion or subconjunctival injection of saline was varied with the copper stick or application of 2 per cent. silver nitrate. Corneal ulcers are usually treated with an application of silver nitrate gr. LX to $\mathfrak{z}_{i}$ to the whole eye followed by irrigation. If this is not successful the cautery is used. 
Pterygium is treated best by excision, Holland having tried the other methods for many years. Trichiasis is treated by electrolysis in mild cases and when associated with entropion by the KaltAnagnostiki operation in which a wedge of tarsal plate is removed. Chronic glaucoma is treated either by Elliot's trephine or a broad iridectomy, Holland finding little to choose between the results of each. Congenital cataracts are often treated by curette evacuation, so as to avoid repeated needlings.

Cataract extractions averaged 32 daily. The table below shows the number done and the main complications. The visual results are difficult to assess, the great majority of the patients being illiterate as well as adverse to returning from ward to hospital for any purpose such as testing vision. Finger counting at 1 metre without correction was therefore the standard of acuity. Approximately 95 per cent. of cases reach this standard. Intracapsular extractions were generally done and of these the greater number were done by a modification of Smith's method and the remainder by using Arruga's or Kalt's forceps.

$\begin{array}{crrrrrrr}\begin{array}{c}\text { Type of operation } \\ \text { Intracapsular }\end{array} & \text { No. } & \begin{array}{c}\text { Capsule } \\ \text { burst }\end{array} & \begin{array}{c}\text { Vitreous } \\ \text { lost }\end{array} & \begin{array}{c}\text { Expulsive } \\ \text { haemorrbage }\end{array} & \text { Infection } & \begin{array}{c}\text { Lens } \\ \text { couched }\end{array} \\ \text { Smith - } & -836 & 72 & 35(4 \cdot 2 \%) & 9 & 11(1 \cdot 3 \%) & - \\ \text { Forceps - } & - & 82 & 20 & 4(4 \cdot 9 \%) & - & - & - \\ \text { Capsulotomy } & - & 433 & - & 8(1 \cdot 8 \%) & 2 & 7(1 \cdot 6 \%) & - \\ \text { Vectis delivery } & - & 69 & - & - & 2 & 1 & 3 \\ \text { Extruded lens } & - & 7 & - & - & 2 & - & - \\ \text { Total } & 1,427 & & & & & \end{array}$

Holland prefers the intracapsular operation for various reasons set out below, and about two-thirds of the cataract extractions are done in this way annually.

(1) No needling operation later.

(2) Less post-operative reaction. Eye is usually white in 4 days.

(3) Shorter stay in hospital, averaging 10 days.

(4) Less dressings required.

(5) Less tendency to sepsis, often due to capsule or lens matter being left in the wound.

(6) No need to wait for cataract becoming mature.

(7) Less tendency to iritis; e.g., in 1929 there was post-operative iritis in 5.3 per cent. of intracapsular extractions and 8.0 per cent. of extracapsular extractions. In all cases there was $5 \cdot 6$ per cent. of iritis after complete iridectomy, $2 \cdot 5$ per cent. after no iridectomy, and 1.9 per cent. after peripheral iridectomy. Factors favouring iritis were found to be hyphaema, lens matter and capsule in the anterior chamber.

Holland attempts the intracapsular method on all cases except the following :- 
(1) Congenital cataract.

(2) Juvenile cataract.

(3) Black cataract.

(4) Individuals with prominent eyes, not necessarily myopic.

(5) Tension more than $35 \mathrm{~mm}$.

(6) Traumatic cataract.

(7) Cataract secondary to iritis.

(8) After sufficient pressure has been used and the lens has not presented.

The technique is as follows:-Facial nerve block, homatropine 1 per cent. with cocaine 2 per cent. Tension taken with McLean's tonometer. Irrigation of subconjunctival sac with 1/2000 hydrarg. perchlor., which was dried off with a swab at once or else it left a temporary corneal opacity. Large section across the horizontal limbal equator, care being taken to avoid an intracorneal incision. Peripheral or complete iridectomy, the former being preferable but the latter causing less resistance to the delivery of the lens. Spoon and strabismus hook were now used together. Pressure by means of a flat lens spoon on the sclera about $3 \mathrm{~mm}$. from the limbus at 6 o'clock and pressure with point of strabismus hook at and along limbus each way from 6 o'clock. The lids are controlled by Smith's speculum until expression of the lens is attempted, when the speculum is removed and the upper lid retracted by an expert assistant. If the lens will not present after reasonable pressure has been made (and this occurs from my observation in roughly 20 per cent. of cases of senile cataract suitable for this technique, and of these the majority are under about 55 years of age) the speculum is replaced and the lens expressed after capsulotomy. The lens does not tumble except rarely. After iris toilet a drop or two of 2 per cent. mercurochrome is applied, no subconjunctival or corneal suture being used. The eyes are bandaged and in the absence of pain the bandage is not removed until 5 days afterwards and 3 days in the case of extracapsular extraction. The after-treatment lasts at least 10 and 14 days respectively.

Criticisms of this method are :-

(1) Knowledge of "sufficient pressure" comes only with experience, and while acquiring this, vitreous is liable to be lost.

(2) Vitreous loss is more common than in the extracapsular method (4.2 per cent. and 1.8 per cent.). However, only 0.5 per cent. of "vitreous loss" cases are responsible for poor vision (H.M. or less) on leaving hospital.

(3) Expulsive haemorrhage is more likely. However, the patients at Shikarpur are usually of poor physique and arterio-sclerosis is common, while at Quetta operating on Baluchis, Brahuis, Pathans and others, expulsive haemorrhage is much less common. 
(4) The drawn up pupil is more common, whether or not iridectomy has been done. It may occur from a patient squeezing his eye after operation, and it does not always follow vitreous loss or bad replacement of iris pillars. Some cases occur with no obvious cause. Such eyes are in all probability predisposed to retinal detachment.

(5) To open the bandage on the third or fifth day saved a great deal of dressings, but on the other hand several iris prolapses occurred, pupils should have been dilated earlier, and two or three cases of sepsis were not discovered until too late.

For the first time at Shikarpur, a series of intracapsular extractions were performed with forceps. Arruga's pattern were generally used and a few were done with Kalt's, with the "toe" or "heel" of a strabismus hook pushing from below to assist in tumbling the lens. None of us had watched an expert using this method and it was difficult to have time for all the details of technique. Undoubtedly results would have been better, particularly as regards having fewer capsules burst, if more attention had been paid to detail. These include the following:-(1) Maximum mydriasis with subconjunctival injection of m.ii of $1: 1000$ adrenalin. Often a capsule burst owing to a too rigid sphincter iridis and once, a contracted pupil obscuring vision, the surgeon caught hold of the iris below in error, causing an iridodialysis.

(2) Retrobulbar or Tenon's capsule novocaine anaesthesia is of great assistance. The use of forceps sometimes takes as long as a minute or more, and the most willing patient will begin to strain if his sensitive iris is being touched for that period.

(3) Suture of rectus superior muscle.

(4) Blascovics' or similar speculum.

(5) Temporary corneal suture of Gomez-Marquéz and two conjunctival sutures at the finish.

(6) The forceps must be introduced with great care, or else a thin anterior capsule will be ruptured. They must grip the anterior capsule as low down as possible at 6 o'clock and must not be opened more than $2 \mathrm{~mm}$. to do so.

The majority of cases were done by " tumbling," and it was found that the capsule burst most frequently just after the lens had started to tumble, and nearly as frequently just as it was delivered. It is advisable to use more forceps pull than strabismus hook push at first, and vice versa directly the lens was definitely tumbling. The "heel" of the strabismus hook is used, and the "toe" if extra pressure is required at one spot. There should be no hurry. Often the lens took 20 seconds to deliver and sometimes much longer. If the lens is not "followed up" with light pressure from the strabismus hook, and the capsule bursts, the lens may fall back into 
the vitreous. "Burst capsule" may be a serious complication, for the posterior capsule has been dislocated and unless the capsule and retained cortex can be moved entire; a very dense after-cataract will result. Even if the capsule has been removed the difficulty of milking out flocculent cortex without loss of vitreous may be considerable.

Complete iridectomy should generally be avoided for the following reasons:-

(1) Optical effects.

(2) Hyphaema may obscure the surgeon's vision.

(3) It is not more likely to prevent iris prolapse than peripheral iridectomy.

(4) Maximal mydriasis is more efficient in overcoming the iris sphincter.

Complete iridectomy should always be performed if satisfactory mydriasis does not occur.

It was found that "striate keratitis" or "traumatic striate opacity of the cornea" was almost the rule after extracting with forceps. This usually disapppeared after a few days but in a few cases had not gone after three weeks. These may have been made worse by the preliminary conjunctival irrigation with 1:2000 hydrarg. perchlor.

Without discussing the relative merits of extracapsular and intracapsular operations, or of the various types of intracapsular operations, certain observations may be made. In extraction with forceps by "tumbling" the lens, less pressure is exerted on the globe than in the modified Smith's method. Also certain senile cataracts in younger patients may be removed with the forceps which by the modified Smith's method would not be extracted. This year hardly any cataracts were extracted by forceps from above, without tumbling, and no figures are available.

Iris prolapse occurs about equally commonly in the "modified Smith's" intracapsular and extracapsular operations. In 1923 and 1924 in all cases of cataract extraction there were 5 per cent. of iris prolapse and 4.6 per cent. of incarceration of iris. I should say that the percentages were appreciably lower this year. If iris prolapse occurred it was cauterised or excised, preferably under general anaesthesia. Often, however, the patient refused a further operation, and Holland says that it is very rare to see an infection follow an.iris prolapse.

Detachment of the retina is held by some to be more common after intracapsular extraction, and others would deny this. Few would deny, however, that vitreous loss can be a predisposing cause of retinal detachment. Holland has no statistics on this point but says that the complication is very rare indeed, and that if it occurred at all commonly surely he would see such a case, with the large 
number of patients he has. He finds that patients usually return if the eye which has been operated on becomes partially blind. At Shikarpur this year we saw only three cases of retinal detachment and only one of these followed cataract extraction. A catholysis and diathermy set were in readiness but the operable cases (two out of three) refused operation. Dick, of Lahore, finds the condition very rare and no commoner after the intracapsular operation. For the visiting surgeon Shikarpur is a gold mine for operative work, and provides endless possibilities for experience and research in ophthalmology.

\section{REFERENCES}

(a) Holland, H. T.-Ind. Med. Gaz., Vol. XLIX, No. 6, p. 213, 1914.

(b) Ind. Med. Gaz., Vol. LVI, No. 6, p. 212, 1921.

(c) Cruickshank, M. M.-Ind. Med. Gaz., Vol. LVIII, p. 461, 1923.

(d) Observations on complications following 2,777 cases of cataract extraction. 1924.

(e) Holland, H. T.-Arch.f. Ophthal., Vol. LIII, No. 2, p. 155, 1920.

$(f)$ Fisher, W. A., and Holland, H. T.-Eye, Ear, Nose and Throat Monthly, January, 1925.

(g) Holland, H. T.-Trans. Ophthal. Soc. U K., Vol. XLIX, p. 393, 1929.

(h) Woodruff, H. W.-Trans. Ophthal. Sect., Amer. Med. Assoc., p. 276, 1931.

(i) Shapland, C. Dee.-Trans. Ophthal. Soc. U.K., Vol. LIV, p. 178, 1934.

\section{ANNOTATION}

\section{Sight-testing for Employees}

With reference to our annotation on Eyesight in Industry in the September number, p. 508, it may be of interest to allude to a method whereby the nursing sister attached to the works or even a lay person such as an overseer can rapidly sort out those employees who are likely to benefit from a detailed eye examination from those with normal vision.

Such a method is supplied by the "Stereosette," and by the courtesy of Theodore Hamblin, Ltd., we have been able to examine a specimen of this instrument. We understand that it has been installed in some factories and that there it has the approval of welfare officers as a useful adjunct to their departments.

It is not an instrument for the prescribing of spectacles. It is a stereometer supplied with nine stereograms. The routine is simple, qualitative rather than quantitative; and rapidly discloses errors that need attention.

The tests take about five minutes; the examiner need not have a specialised knowledge of optics or of eyesight, and the results are recorded on an "efficiency pad," which is supplied with the 